\title{
Monosomy 8p: an easily overlooked syndrome
}

\author{
A H J T BRÖCKER-VRIENDS*, P D MOOIJ* $\dagger$, F VAN BEL , \\ G C BEVERSTOCK§, AND J J P VAN DE KAMP*† \\ From the Departments of Clinical Genetics*, Pediatrics $\dagger$, Neonatology $\ddagger$, and Human Genetics $\$$, University of \\ Leiden, The Netherlands.
}

SUMmARY Two patients with partial monosomy of the short arm of chromosome 8 are described. Their clinical features were very similar. Comparison with previously reported patients confirms the existence of an $8 \mathrm{p}-$ syndrome. The importance of cytogenetic investigations in all infants with major congenital heart defect and facial dysmorphism or microcephaly or both is stressed.

Since the publication of the first case report of partial monosomy of the short arm of chromosome 8 by Lubs and Lubs in $1973,{ }^{1}$ eight more patients have been described. ${ }^{1-9}$ There are many common features, particularly in younger patients, indicating the existence of an $8 p-$ syndrome. We describe two more patients with partial monosomy of $8 p$ in whom at first a chromosomal abnormality was not considered.

\section{Case reports}

CASE 1

A girl was born at term after an uneventful pregnancy to a 38 year old gravida 2, para 1 mother; birth weight $2600 \mathrm{~g}$, length $47 \mathrm{~cm}$, head circumference $30 \mathrm{~cm}$ (all <10th centile). Soon after birth she became cyanotic and a systolic murmur was noticed. Cardiac catheterisation revealed tetralogy of Fallot with double outlet right ventricle and a left sided superior vena cava.

At the age of 3 years she was referred for chromosome studies because of craniofacial dysmorphism and psychomotor retardation. Physical examination revealed length, weight, and head circumference to be well below the 10th centile. There was a prominent occiput, small facies with narrow prominent forehead, hypertelorism, narrow upward slanting palpebral fissures, short stubby nose, thin mouth, ogival palate, and irregularly implanted teeth. Ears were low set and malformed. Nipples were wide set and hypoplastic. Bilateral inguinal herniae were present. Extremities showed cubitus valgus, long small fingers, irregularly placed Received for publication 31 December 1984. Accepted for publication 7 January 1985 . toes with the second overriding the third, and hypoplasia of the fifth toe. The child died of cardiac failure at the age of 5 years.

\section{CASE 2}

A girl was born at term after a normal pregnancy to a 31 year old gravida 2 , para 0 mother; birth weight $1930 \mathrm{~g}$, length $45 \mathrm{~cm}(<10$ th centile). After three days her condition deteriorated and she was transferred to our neonatal intensive care unit for evaluation and treatment. Physical examination revealed a slightly dysmorphic facies with narrow, upward slanting palpebral fissures, short stubby nose, retrognathia, low set ears with sparsely curved helix, and a head circumference of $31 \mathrm{~cm}(<10$ th centile). Both hands had a low inserted thumb with overlap of the first finger over the second and of the fifth over the fourth. She had rocker bottom feet with a sandal gap, short first toes, and hypoplastic toenails. A loud, rough systolic murmur was heard. Echocardiography indicated a persistent ductus arteriosus and a large ventricular defect. Because of these multiple defects a chromosomal analysis was performed. An $E$ coli sepsis was treated with antibiotics. However, her condition deteriorated rapidly and she died on the tenth day. At necropsy hypoplasia of the brain was found. The heart defect consisted of a complete AV canal with a monoatrium and double outlet right ventricle, persistent ductus arteriosus, and left superior vena cava.

\section{CYTOGENETIC INVESTIGATIONS}

Orcein stained chromosome preparations of case 1 revealed a partial monosomy of the short arm of chromosome 8. Although the chromosomes were unbanded, it was clear that approximately half of the short arm was missing. $\mathrm{G}$ banded chromosomes 

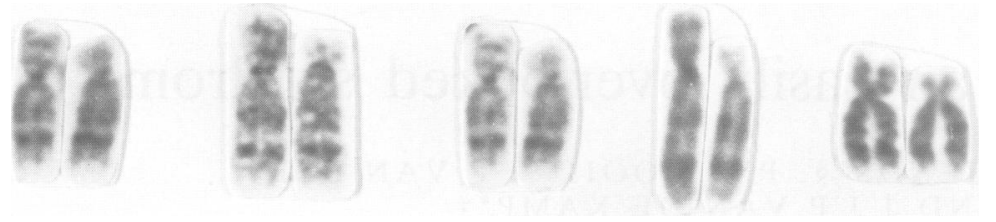

FIGURE $G$ banded chromosomes 8 of patient 2 .

of case 2 revealed partial monosomy of the short arm of chromosome 8 , defined as $46, \mathrm{XX}, \operatorname{del}(8)$ (pter $\rightarrow$ p21) (figure). The parents of both patients had a normal karyotype.

\section{Discussion}

The phenotypic abnormalities of case 1 are strikingly similar to those of the patients described by Leisti and Aula $^{2}$ and Reiss et al. $^{3}$ In particular, the similarity of the facies is remarkable including delicate features with narrow forehead, narrow palpebral fissures, short stubby nose, and thin lips. These facial abnormalities seem to become less evident with age, as demonstrated by the patient of Orye and Craen, ${ }^{4}$ explaining why older patients have a less characteristic facies. ${ }^{5-7}$ Only the patient described by Beighle $e t$ al $^{8}$ is dissimilar, probably because a different segment of the short arm of chromosome 8 was involved.

The clinical findings in our patients and in the previously reported patients are summarised in the table. Since the phenotypic expression of monosomy $8 \mathrm{p}$ might be influenced by a simultaneous imbalance of another chromosome segment, the patients in whom the monosomy $8 \mathrm{p}$ was due to an unbalanced translocation $^{19}$ are excluded. Apart from the facial features, the most common clinical findings were

TABLE Clinical findings in patients with partial monosomy $8 p$.

\begin{tabular}{lllll}
\hline Clinical findings & $\begin{array}{l}\text { Reported } \\
\text { patients }\end{array}$ & $\begin{array}{l}\text { Case } \\
I\end{array}$ & $\begin{array}{l}\text { Case } \\
2\end{array}$ & $\begin{array}{l}\text { All } \\
\text { patients }\end{array}$ \\
\hline Antenatal growth defect & $3 / 7$ & - & + & $4 / 9$ \\
Postnatal growth defect & $5 / 7$ & + & & $6 / 8$ \\
Mental retardation & $7 / 7$ & + & & $8 / 8$ \\
Microcephaly & $5 / 7$ & + & + & $7 / 9$ \\
Narrow forehead & $6 / 7$ & + & - & $7 / 9$ \\
Prominent occiput & $2 / 4$ & + & - & $3 / 6$ \\
Narrow palpebral fissures & $5 / 7$ & + & + & $7 / 9$ \\
Epicanthus & $5 / 7$ & - & - & $5 / 7$ \\
Short stubby nose & $3 / 7$ & + & + & $5 / 7$ \\
Thin mouth & $4 / 7$ & + & - & $5 / 9$ \\
Ogival palate & $3 / 4$ & + & - & $4 / 6$ \\
Retrognathia & $4 / 7$ & - & + & $5 / 9$ \\
Dysplastic ears & $5 / 7$ & + & + & $7 / 9$ \\
Widely set nipples & $5 / 5$ & + & - & $6 / 7$ \\
Cardiac defect & $4 / 7$ & + & + & $6 / 9$ \\
\hline
\end{tabular}

postnatal growth retardation, moderate or severe mental retardation, microcephaly, dysplastic ears, widely set nipples, and major cardiac defect. Although most of these features are non-specific, the combination of microcephaly, congenital heart defect, and delicate facies indicates a distinctive phenotype associated with monosomy $8 \mathrm{p}$. As demonstrated in our two patients, facial dysmorphism and microcephaly can easily be overlooked in infants with a severe congenital cardiac defect. We regard the combination of these defects as a strong indication for chromosome analysis. Although in most of the patients monosomy $8 \mathrm{p}$ resulted from a de novo deletion, cytogenetic investigation in the parents is recommended to exclude a familial translocation with a higher risk for unbalanced progeny.

\section{References}

1 Lubs HA, Lubs ML. New cytogenetic technics applied to a series of children with mental retardation. In: Casperson $\mathrm{T}$, Zech L, eds. Chromosome identification technique and application in biology and medicine. Nobel Symposia 23. New York London: Academic Press, 1973:241-50.

2 Leisti J, Aula P. A case of deletion of the short arm of chromosome 8. Birth Defects 1977;XIII(3b):187-94.

${ }^{3}$ Reiss JA, Brenes PM, Chamberlin J, Magenis RE, Lovrien EW. The 8p- syndrome. Hum Genet 1979;47:135-40.

4 Orye E, Craen M. A new chromosome deletion syndrome. Report of a patient with $46, X Y, 8 p$ - chromosome constitution. Clin Genet 1976;9:289-301.

${ }^{5}$ Bresson JL, Noir A, Scherrer M. Délétion partielle du bras court du chromosome 8. Ann Genet (Paris) 1977;20:70-2.

${ }^{6}$ Rodewald A, Stengel-Rutkowski S, Schulz P, Cleve H. New chromosomal malformation syndromes. I. Partial monosomy 8p. An attempt to establish a new chromosome deletion syndrome. Eur J Pediatr 1977;125:45-85.

7 Taillemite JL, Channarond J, Tinel H, Mulliez N, Roux C. Délétion partielle du bras court du chromosome 8. Ann Genet (Paris) 1975;18:251-5.

8 Beighle C, Karp LE, Hanson JW, Hall JG, Hoehn H. Small structural changes of chromosome 8. Hum Genet 1977;38: 113-21.

9 Guanti G, Mollica G, Polimeno L, Maritato F. rDNA and acrocentric chromosomes in man. I. rDNA levels in a subject carrier of a $8 \mathrm{p} / 13 \mathrm{p}$ balanced translocation and his unbalanced son. Hum Genet 1976;33:103-7.

Correspondence and requests for reprints to $\mathrm{Dr}$ A $\mathbf{H}$ J T Bröcker-Vriends, Centre for Clinical Genetics, University Hospital of Leiden, Rijnsburgerweg 10, 2333 AA Leiden, The Netherlands. 